\title{
Sea Surface Temperature variations over Kuroshio in the East China Sea
}

\author{
Jiahao Wang ${ }^{1}$, Aibo Chen ${ }^{2}$, and Huaming Yü, ${ }^{3}$, \\ ${ }^{1}$ College of Meteorology and Oceanography, National University of Defense Technology, Nanjing, People's Republic of China \\ ${ }^{2}$ Nanjing Foreign Language School, Nanjing, People's Republic of China \\ ${ }^{3}$ College of Oceanic and Atmospheric Sciences, Ocean University of China, Qingdao, People's Republic of China
}

\begin{abstract}
Using daily OISST. V2 data with a spatial resolution of $0.25^{\circ} \mathrm{x} 0.25^{\circ}$ from NOAA, Sea Surface Temperature (SST) variations over Kuroshio in the East China Sea during the past twenty-five years (19932017) are studied. The results show that the distribution of SST decreases from south to northwest and northeast, and the spatial gradient is large in winter and spring while weak in summer and autumn. Besides, Kuroshio warm tongue has the feature of "strong in spring while weak in summer". Moreover, interannual variability of SST over Kuroshio synchronous warming/cooling dominated, followed by the northwestsoutheast phase changing, and it shows a close connection with ENSO. The spectrum analysis shows that interannual variability of SST has significant semi-annual and 28 months period of oscillation. In addition, there are significant 8 months-lag correlations between averaged SST anomaly of Kuroshio in the East China Sea and ENSO index.
\end{abstract}

\section{Introduction}

Kuroshio Current is the representative of western boundary current in the North Pacific subtropical gyre, and has the characteristics of warm and salt water, narrow current amplitudes and large fluxes. It's very important to transports mass, moment, heat and fresh water in the meridional direction ${ }^{[1]}$. Kuroshio enters the East China Sea on the eastern coast of Taiwan, flows northeastward and leaves from the southwest of Kyushu ${ }^{[2]}$.

Sea surface temperature (SST) is an important geophysical parameter of Kuroshio and has been investigated by many oceanographers. Kuroshio is a broad current; therefore, many factors may influence its SST not only itself but also solar radiation, winds, mesoscale eddies and so on. SST of Kuroshio in the East China Sea has obvious multi-scale variations including seasonal, interannual and decadal variations ${ }^{[3]}$. In the seasonal scale, SST of Kuroshio is warm (cold) in summer (winter), and the warmest (coldest) is in August (February/March) ${ }^{[4]}$. It has the period of interannual variations about 2-7 years, which is closely linked with El Niño-Southern Oscillation (ENSO) event ${ }^{[5,6]}$. Besides, it has 20-year time scales and associates with the Pacific Decal Oscillation (PDO) [7]. Due to the limitation of observational data, the investigations about Kuroshio temperature are limited ${ }^{[8]}$.
The paper is organized as follows: section 2 describes the used data and methods; section 3 discusses the SST variations over Kuroshio in the East China Sea; section 4 provides conclusions.

\section{Data and Methods}

The study area is located between $22^{\circ} \mathrm{N}-34^{\circ} \mathrm{N}$ and $122^{\circ} \mathrm{E}$ $136^{\circ} \mathrm{E}$, and SST data used are from Optimum Interpolation Sea Surface Temperature Version 2 (OISST V2), which provided by National Oceanic and Atmospheric Administration (NOAA) Earth System Research Laboratory. The data are daily averaged, available for the whole globe with a spatial resolution of $0.25^{\circ} \times 0.25^{\circ}$. In this paper, we use 1993-2017 data and average them monthly. Monthly nino3 index provided by NOAA is used to define the strength of ENSO event. It is the averaged SST anomaly of an area $\left(150^{\circ} \mathrm{W}-90^{\circ} \mathrm{W}, 5^{\circ} \mathrm{S}-5^{\circ} \mathrm{N}\right)$.

The SST climatology is given as the mean of monthly data. The empirical orthogonal function (EOF) is utilized to find out how Kuroshio's SST interannual variability performs in the East China Sea. Power Spectral Density (PSD) is carried out to discussing the main periods of the time series. Lead-lag correlation analysis is used to study the relationship between SST anomaly over Kuroshio in the East China Sea and ENSO index.

\footnotetext{
$\overline{{ }^{*} \text { Corresponding author: hmyu@ouc.edu.cn }}$
} 

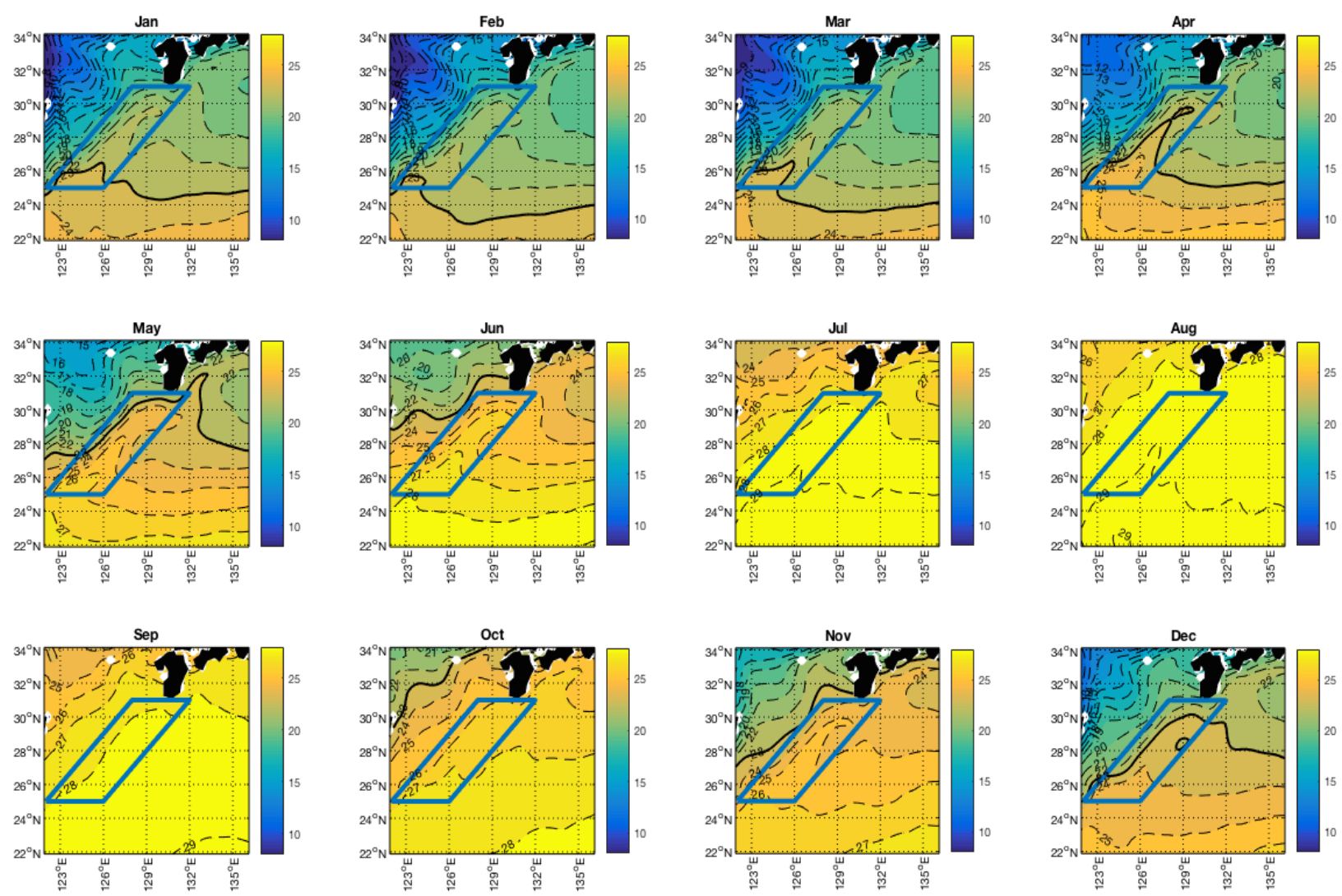

Fig 1. The climatological SST distribution based on 1993-2007. The blue box is region of Kuroshio warm tongue.

\section{Results}

\subsection{Seasonal variability}

The climatological SST distribution based on 1993-2007 is shown in Fig 1. The seasonal variations are obvious that SST is lower in winter and spring than in summer and autumn. SST weakens gradually northwestward and northeastward from the Kuroshio region in the East China Sea. The spatial gradient is large in winter and spring while weak in summer and autumn. Therefore, Kuroshio warm tongue which extends from southern area to Kyushu Island is very strong in spring and wear off in summer. Yu Fei et al. (2010) consider it's reasonable to choose warm tongue as a qualitative index to study the path of warm

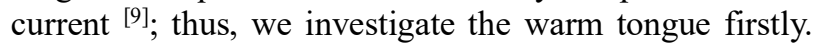
The typical warm tongue occurs in winter and spring, and the $23^{\circ} \mathrm{C}$ isotherm has good representativeness, as shown in Fig 1. We study the movement of $23^{\circ} \mathrm{C}$ isotherm, and chose the northest latitude of $23^{\circ} \mathrm{C}$ isotherm in January (April) as the intensity characteristic index of Kuroshio in Winter (Spring). Fig 2 reveals that on the whole, the $23^{\circ} \mathrm{C}$ isotherm can reach higher latitude in spring (about $30^{\circ} \mathrm{N}$ ) than in winter (about $26-28^{\circ} \mathrm{N}$ ). Therefore, Kuroshio is stronger in spring than in winter. We calculate the correlation coefficient of winter and spring index. It is 0.33 and above $95 \%$ confidence level. The intensity of Kuroshio has positive correlation between winter and spring. Fig 2 also shows that the index has obvious interannual variability. Both of them reach the peak in 1998 and valley in 2011.

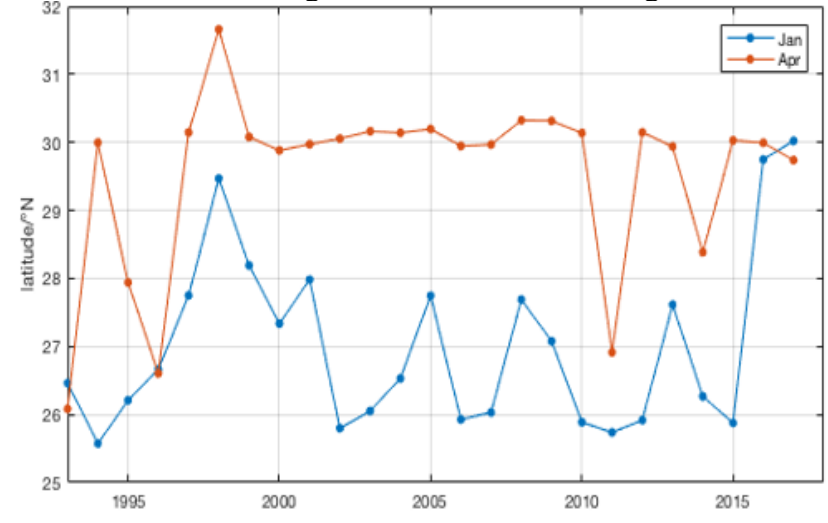

Fig 2. the northest latitude of $23^{\circ} \mathrm{C}$ isotherm in January (blue) and April (red).

\subsection{Interannual variability}

The superior mode of the SST interannual variability is performed by EOF analysis. The first three modes contribute $40.8 \%, 13.9 \%$ and $5.8 \%$ to the total variance and satisfy the significance test. Thus, we emphatically discuss the first two modes. Fig 3 and Fig 4 depicts their spatial distribution and related time coefficient.

The first mode demonstrates that the dominant interannual variability of Kuroshio's SST in the East China Sea was synchronous warming/cooling. There are two distinct cold/warm water area. When the first PC time series greater than zero, cold water area is on the southwest of Jeju Island and the center is at $126^{\circ} \mathrm{E}, 30.5^{\circ} \mathrm{N}$. It's the East China Sea cold eddy whose formation and evolution are linked well with ocean and atmospheric circulation. When the first PC time series less than zero, 
broad warm water area is on the southeast of Kuroshio axis. It's the western Pacific warm pool where tropical cyclones happen frequently. In this mode, the effects of the ENSO event on Kuroshio's SST in the East China Sea are also revealed, in that SST rises distinctly in 1998, 2001 and 2016, when strong El Niño events took place. The second mode contributes $13.9 \%$ to the total variance, which is much less than the first mode. It demonstrates that the evigenvector weakens gradually from greater than zero in northwest to less than zero in southeast. Kuroshio axis is the boundary. The second PC time series was mostly greater than zero before 2010 and less than zero after 2010 . Combing space field, we can find SST in the southeast (northwest) of Kuroshio increases (decreases).

We use PSD analysis to analyze the periods of Kuroshio's SST in the East China Sea. The peak of first PC time series is 7 months and those of second PC time series are 28 and 9 months. Therefore, the first mode primarily shows the semi-annual variations; the second mode mainly reveal the interannual variations, and the period of 28 months is similar to the period of ENSO ${ }^{[10]}$. We calculate the correlation coefficient between averaged SST anomaly of the study area and nino3 index. It's 0.0016 without lead-lag. While lag 8 months, it reaches 0.37 (above 95\% confidence level). Thus, the SST over Kuroshio in the East China Sea linked well with ENSO
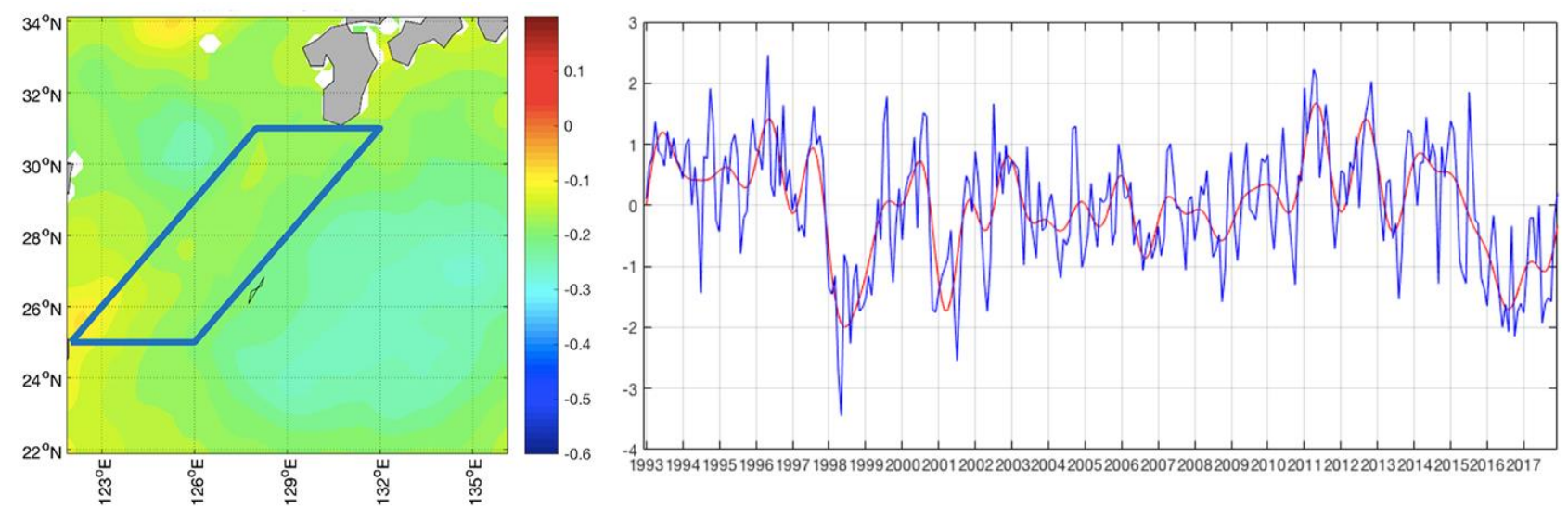

Fig 3. The first evigenvector field of monthly SST anomalies (left) and the associated PC time series (right) based on 1993-2017.
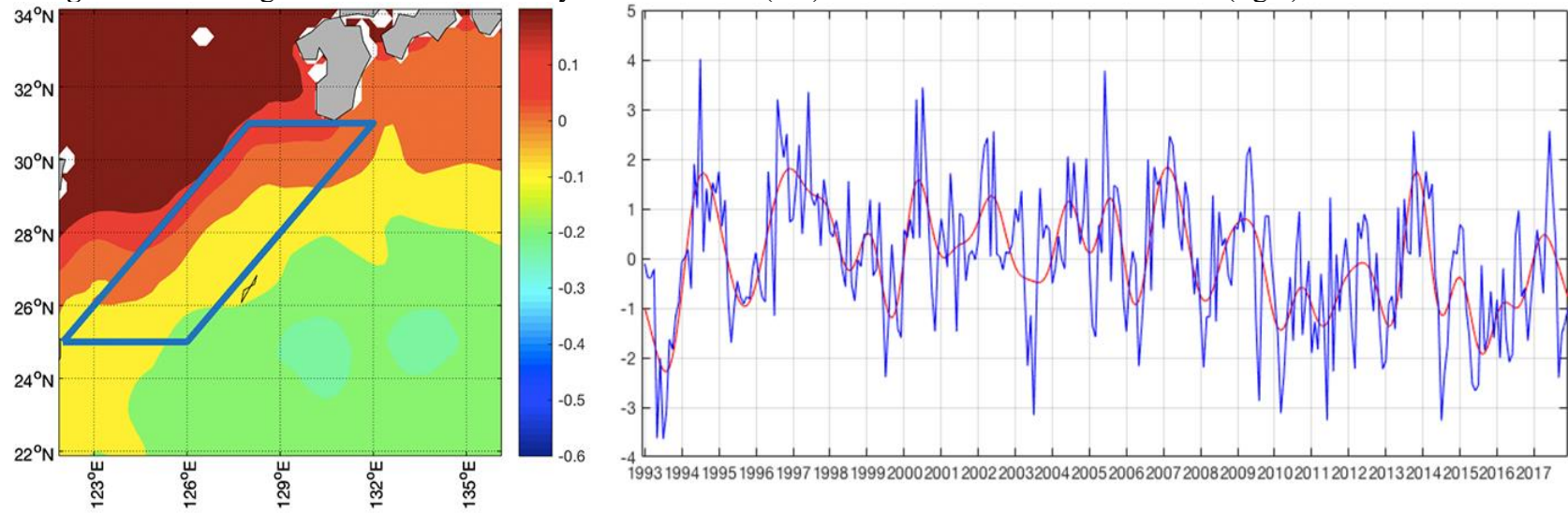

Fig 4. The second evigenvector field of monthly SST anomalies (left) and the associated PC time series (right) based on 1993-2017.

\section{Conclusion}

Based on the $0.25^{\circ} \times 0.25^{\circ}$ daily OISST. V2 data for the period 1993-2017 provided by NOAA Earth System Research Laboratory, the characteristics and regularities of SST variations over Kuroshio in the East China Sea are analyzed. The results show that the distribution of SST overall decreases from south to northwest and northeast, and SST gradient is greater in winter than in summer. Besides, the Kuroshio warm tongue has the feature of "strong in spring while weak in summer". Moreover, interannual variability of SST over Kuroshio synchronous warming/cooling dominated, followed by the northwest southeast phase changing, and shows a close connection between variations of Kuroshio's SST and ENSO. The spectrum analysis shows that interannual variability of SST has significant 28 months period of oscillation and quasi half a year's time scale. What's more, the averaged SST anomaly of Kuroshio in the East China Sea has 8 months-lag correlations with ENSO index, and the correlation coefficient could reach 0.37 (above 95\% confidence level). However, due to the limitation of data, we haven't studied decal or larger timescale. It needs to be discussed in future.

\section{References}

1. A. M. Macdonald and C. Wunsch, An estimate of global ocean circulation and heat fluxes. Nature. 382, 436-439 (1996)

2. C. Zhang and G. Chen, SST variations of the Kuroshio from AVHRR observation. Chin. J. Oceanol. Limnol. 24(5),245-351 (2006)

3. N. Sun, Variations of Sea Surface Temperature over 
Kuroshio in the East Sea and Its relationship with Elnino and Global Warming. Master Dissertation. Ocean University of China. (2009) (in Chinese)

4. Y. Li, The influence of SST at Kuroshio on precipitation in China during rainy season and relationship between SST and main circulation over the east Asia. J. Mete. Sin. 9(3),263-275 (1989) (in Chinese)

5. T. Hinata, Seasonal variation and long-term trends of the oceanographic conditions along a fixed hydrographic line crossing the Kuroshio in the East China Sea. Oceangr. Mag. 45:9-32 (1996)

6. S. Imawaki, H. Uchida, H. Ichikawa et al., Satellite altimeter monitoring the Kuroshio transport south of Japan. Geophys. Res. Lett. 28:17-20 (2001)
7. S. Wang, Y. Guan, Z. Li, et al., Preliminary analyses on characteristics of sea surface temperatures in Kuroshio and its extension and relations to atmospheric circulations. Acta Phys. Sin. 61(16):169201 (2012) (in Chinese)

8. X. Wang, C. Li, Decadal variation of spring SST and wind field in the East China Sea Kuroshio. J. Mar. Sin. 31(4):10-16 (2013) (in Chinese)

9. F. Yu, Z. Zhang, X. Diao, et al., Observational evidence of the Yellow Sea warm current. Chin. J. Oceanol. Limnol. 28(3):677-683 (2010)

10. H. Wu and J. Yu., Study on quasi-biennial variability in lower stratosphere. J. NJ. Inst. mete. 23(3):305312 (2000) (in Chinese) 